\title{
Bölgelerin Birbirlerinin İhracat Deseni Çeşitliliğine Etkisi: Düzey2 Bölgeleri Üzerine Bir Mekânsal Panel Veri Analizi
}

\author{
Mehmet AYDINER*
}

\begin{abstract}
Öz
Bu çalışmanın amacı Türkiye'deki 26 İBBS Düzey2 bölgelerinin birbirlerinin ihracat ürünü deseni ve ihracat pazarı çeşitliliğine etkisini araştırmaktır. Mekânsal Panel Veri Yöntemi kullanılarak yapılan çalışmada 26 Düzey2 bölgesinin 2002-2015 dönemindeki çeyrek dilim ihracat ve ithalat verileri kullanılmıştır. Mekânsal Ağırlık Matrisi Vezir Komşuluğu kuralına göre oluşturulmuştur. Mekânsal etkinin olup olmadığının tespiti ve Mekânsal Gecikmeli Model (SAR) ile Mekânsal Hata Modeli (SEM) modelleri arasında uygun modeli seçmek için LM testi kullanılmıștır. LM testi sonuçları Düzey2 bölgeleri arasında mekânsal bağımlılı̆ın bulunduğunu göstermektedir. Hausman Testi sonuçlarına göre uygun model Sabit Etkiler Modeli, LM testi sonuçlarına göre uygun Mekânsal Ekonometrik Model ise Mekânsal Hata Modelidir. Hausman testi sonuçları da Sabit Etkili Modelin çalışma için en uygun model olduğunu göstermektedir. Sabit Etkili Panel Mekânsal Hata Modeli ile yapılan tahmin sonuçlarına göre, Düzey2 bölgeleri arasındaki mekânsal otokorelasyon katsayısı $\lambda$ 0.08'dir. Düzey2 bölgeleri için ithalatın $\% 1$ artması ürün çeşitliliğini $\% 0.15$ artırmaktadır. İhracatçı firma sayısının \%1 artması çeşitliliğ̈i \%0.19 artırırken, ihracatın \%1 artması ise çeşitliliğin \%0.16 artmasını sağlamaktadır. Bölgelerin birbirlerinin ihracat pazar sayısı üzerine etkisi bulunmamaktadır.
\end{abstract}

Anahtar Kelimeler: İhracat, İhracat Çeşitliliği, Mekânsal Panel, Mekânsal Bağımlllık, Mekânsal Hata, Mekânsal Gecikme Modeli

\section{Effect of Regions on Each Others' Export Composition Diversity: An Spatial Panel Data Analysis for NUTS2 Regions}

\section{Abstract}

The purpose of this study is to examine whether NUTS2 regions have spatial effect on each others' export product and export market diversity. The study uses

Özgün Araştırma Makalesi (Original Research Article)

Geliş Tarihi: 27.01.2016 Kabul Tarihi: 03.01.2017

DOI: http://dx.doi.org/10.17336/igusbd.305641

${ }^{*}$ Gümrük Uzmanı, Gümrük ve Ticaret Bakanlığı, Ankara, Türkiye, E-posta:

mehmetaydiner@yahoo.com 
Sayfa/Page | 182

İGÜ Sos. Bil. Derg., 4 (1), 2017, ss. $181-196$.

2002-2015 quaterly export, import, investment and exporter data of the regions. The method used in the study is Spatial Panel Data. Spatial Weight Matrix was constructed by using queen contiguity rule. LM test was employed to determine existence of spatial effect among regions and to choose the right spatial model between Spatial Lag Model (SAR) and Spatial Error Model (SEM). LM test results show that there exists spatial effect among NUTS2 the regions and the best model is SEM. Hausman test results indicate the best model for the study is fixed effect panel model. Spatial autocorrelation coeeficient $\lambda$ for NUTS2 is 0.08 . The estimation results of SEM Panel Model for NUTS2 suggests that while 1\% increase in total import rise total export $0.15 \%, 1 \%$ incraese in number of exporter and investments increase total export $0.19 \%$ and $0.16 \%$ respectively. There is no spatial effect for number of export market of the regions.

Keywords: Export, Export Diversity, Spatial Panel, Spatial Dependence, Spatial Error Model, Spatial Lag Model

\section{Giriş}

Son 30 yıldır ihracata dayalı büyüme modeli uygulayan Türkiye bu modele bağlı politikalar kapsamında ihracatı artırmak için değişik teşvik ve yardım sistemleri uygulamaktadır. İhracatın artırılmasına yönelik bu teşvikle, destekler ve politikalar olumlu sonuçlar vermiştir. Türkiye'nin ihracatı 2010 yılı sonrası dönemde 150 milyar dolar seviyelerine ulaşmıştır.

İhracatın artırılmasının yanı sıra ihracat ürünlerinin deseni, ürün sepetinin çeşitliliği, ürünlerin katma değerinin yüksek olması ve çok sayıda pazara ihracatın gerçekleştirilmesi de çok önem arz etmektedir. Ürün ve pazar çeşitlendirilmesi hem ihracatın artmasını sağlarken hem de ihracatın dış ülkelerdeki olası gelişmelerden etkilenmesini ve kırılganlığını da azaltmaktadır.

İhracatta ürün çeşitliliğinin artırılmasına yönelik olarak değişik destek ve teşvik politikaları uygulanırken, pazar çeşitliliğinin artırılması için de fuarlara katılım, tanıtım vb. faaliyetler için firmalara destekler sağlanmaktadır. Türkiye 2014 yllında 243 ülke veya serbest bölgeye ihracat gerçekleștirirken 97 fasılda ürün ihraç etmiştir. 2007 yılında 44.700 olan ihracatçı firma sayısı 2014 yılında 61.000 seviyesine ulaşmıştır. 
Tablo 1: Yıllara Göre Toplam İhracatçı Firma Sayısı ve Toplam İhracat (Milyar Dolar)

\begin{tabular}{|l|l|l|l|l|l|l|}
\hline & $\mathbf{2 0 0 9}$ & $\mathbf{2 0 1 0}$ & $\mathbf{2 0 1 1}$ & $\mathbf{2 0 1 2}$ & $\mathbf{2 0 1 3}$ & $\mathbf{2 0 1 4}$ \\
\hline $\begin{array}{l}\text { Firma } \\
\text { Sayısı }\end{array}$ & 48.668 & 50.453 & 53.140 & 56.440 & 60.119 & 63.587 \\
\hline $\begin{array}{l}\text { İhracat } \\
\text { (Milyar \$) }\end{array}$ & 102.1 & 113.8 & 134.9 & 152.4 & 151.8 & 157.6 \\
\hline $\begin{array}{l}\text { İthalat } \\
\text { (Milyar \$) }\end{array}$ & 140.9 & 185.5 & 240.8 & 236.5 & 251.6 & 242.1 \\
\hline
\end{tabular}

Sayfa/Page | 183

Kaynak: TÜİK

İhracatın artırılmasında, ihraç ürünleri deseninin ve pazarın çeşitlendirilmesinde uygulanan teşvik politikalarının yanında çok sayıda faktör etkili olmaktadır. Firmaların pazarlama ve ürün geliştirme stratejileri, yönetim anlayışları, kurumsal yapıları gibi içsel faktör ürün ve pazar çeşitliliğinin artırılmasında etkili olabilmektedir.

Ürün deseni ve pazar çeşitliliğinin artırılmasında firmaların bulundukları sektör ve yerleşik oldukları bölge de etkili olabilmektedir. Örneğin önemli bir tekstil ihracatçısı olan Denizli iline komşu Aydın ilinde son yıllarda tekstil ürünü üreten ve ihraç eden firma sayısı artarken tekstil ihracatı da artmıştır. Aynı şekilde Denizli ili önemli miktarda kablo ihracatı yapmaktadır. Aydın ilinde son yıllarda bu sektöre yönelik tesisler kurulmuş 50 milyon dolardan fazla ihracatı olan firmalar ortaya çımıştır. Benzer şekilde Aydın ilinde yıllardır faaliyet gösteren gıda işleme tesisleri bulunmaktadır. Son yıllarda Denizli ilinde aynı tarım ve gıda ürünlerini işleyen firma sayısı artarken ilin bu sektördeki ihracatı da artmıştır. Bu örnekleri İstanbulTekirdağ, Bursa- Bilecik, Kocaeli- Sakarya, Denizli- Uşak, İzmir-Manisa, KonyaKaraman bazında çoğalmak ve açmak mümkündür. Bu örnekler özelde firmaların, genelde bölgelerin ihracatta birbirini etkilediğini ve birbirlerinden öğrendiğini göstermektedir.

Yukarıda bahsedilen örneklerden bir bölgenin ihracat performansının, ihracat ürün deseni ve pazar çeşitliliğinin komşu bölgeleri etkilediği ve komşu bölgelerden etkilendiği görülmektedir. İhracatta bilgi taşması olarak tanımlanan bu etki konusunda değișik ülkeleri -özellikle bölgelerin birbirlerinin ihracat performanslarına etkisi üzerine- inceleyen çok sayıda çalışma bulunmasına karşın Türkiye üzerine yapılmış çalışma bulunmamaktadır.

Bu çalışmada Türkiye'de bulunan 26 Düzey2 bölgesinin birbirlerinin ihracat ürün deseni çeşitliliğine mekânsal etkilerinin bulunup bulunmadığı, 
Sayfa/Page | 184

İGÜ Sos. Bil. Derg., 4 (1), 2017, ss. $181-196$. varsa etkinin ne düzeyde olduğu araştırılmaktadır. Çalışmada Mekânsal Panel Veri Yöntemi kullanılmıștır.

\section{Literatür}

Dış ticarette bilgi taşması veya mekânsal etki konusunu ele alan literatürdeki çalışmalar genel olarak bölgelerin birbirlerinin ihracat miktarlarına yani ihracat performanslarına etkisini veya bölgelerdeki firmaların birbirlerinin ihracatçı olmalarına etkisini incelemiştir. $\mathrm{Bu}$ çalışmanın konusu olan bölgelerin birbirlerinin ihracat ürün çeşitliliğine etkisini inceleyen çalışmaya rastlanılamamıştır. $\mathrm{Bu}$ sebeple literatür taramasında ulaşılan çalışmalar genelde ürün çeşitlendirmesi ve bilgi taşması dışsallıklarını inceleyen çalışmalardır.

Ürün çeşitlendirmesinin ihracat performansına etkisi literatürde çok az incelenmiş bir konudur. Ürün çeşitlendirmesinin net tanımı bulunmamasının yanında, çeşitlendirmenin ölçütü olarak değişik kriter ve endeksler kullanılmaktadır. Bu kriterlerden en yaygın olanı yoğunluk endeksidir. Yoğunluk endeksi bir ülkenin ihracat gelirinin büyük kısmının hangi ürünler veya ürün gruplarından elde edildiğini ölçmektedir. İhracat yoğunluk olarak veya geniş kapsamlılık olarak büyüyebilir. Yoğun büyüme hali hazırda ihraç edilen ürünlerden elde edilen gelirin artması, kapsamlı büyüme ise ihraç edilen ürün sepetinde ürün sayısının artması olarak tanımlanabilir. ${ }^{1}$

Ürün çeşitlendirmesinin ölçümü ve ihracat performansına etkisi konusunda literatürde değişik ülkeler üzerine çalışmalar bulunmaktadır. $\mathrm{Bu}$ çalışmalarda ürün çeşitlendirmesi ile ihracat gelir artışının doğrusal ilişkiye sahip olmadığını, ilişkinin doğrusal olmayan bir ilişki olduğunu gösterilmiştir. Çeşitlilikteki artış oranı ile ihracat gelirindeki artış oranı aynı değildir. ${ }^{2}$ Şili üzerine yapılan çalışmada dış ticarette yapılan reformların ve döviz kurundaki değer kaybının ihracat ürünü çeşitliliğini artırdığını bildirilmiştir. ${ }^{3}$

$\mathrm{Bu}$ çalışmanın amacı ürün çeşitlendirmesinde mekânsal etkiyi araştırmak olduğundan ürün çeşitliliği ve çeşitlilik artışının ihracat performansına etkisi üzerine çalışmaların yanında dış ticarette mekânsal etkiyi araştıran çalışmalarda incelenmiştir. "Yeni ekonomik coğrafya" tezinde

${ }^{1}$ Oliver Cadot, Celine Carrere ve Vanessa Strauss-Kahn, "Export Diversification: What's behind the Hump?", Review of Economics and Statistics, Vol.93, No:2, 2001, ss. 590-605.

2 Jean Imbs ve Romain Wacziarg, "Stages of Diversification," American Economic Review, 93 (1): 2003, ss. 63-86.

${ }^{3}$ Sheila Gutierrez de Pineres ve Michael Ferrantino, "Export Diversification and Structural Change: Some Comparisons for Latin America", 1997, SSRN Working Paper No. 36321. 
bazı sektörlerin belli bir bölgede yerleşmesinin "birbirlerinden öğrenme ve bilgi taşması dışsallıkları" yoluyla firmaların ihracat yapma ihtimalini artırdığını ileri sürülmüştür. ${ }^{4}$

"Yerel İhracat Taşması" hipotezinde bir firmanın ihracatçı olma ihtimalinin çevresinde çok sayıda ihracatçı bulunması halinde daha yüksek olduğu ileri sürülmüştür. Çevrede çok sayıda ihracatçı firmanın olması dış pazarlar hakkında bilgi sağlarken, ihracat faaliyetine destek sağlayan danışman firmalarının da bu bölgede artmasına neden olmakta dolayısıyla firmanın ihracatçı olmasını kolaylaştırmaktadır. ${ }^{5}$ Fransa'daki firmalar üzerine yapılan çalışmada yerel mekânsal etkinin olduğunu ve çevrede ihracatçı firmaların bulunmasının diğer firmaların da ihracat faaliyetine başlamalarına olumlu katkı yaptığı sonucuna ulaşılırken, bu çevresel etkinin firmaların ihracat performansı üzerine etkisi olmadığını bildirilmiştir.6Macaristan'daki firmalar üzerine yapılan çalışmada ulaşılan sonuçlar çevrede ihracatçı firmaların bulunmasının diğer firmaların ihracatçı olmalarını teşvik ettiğini, mekânsal etkisinin olumlu yönde katkı yaptığını göstermiştir.7İsveç’te bulunan firmalar için, çevrede ihracatçı firmaların bulunmasının ticari ağlar veya mekânsal bilgi yayılması sayesinde yerel firmaların ihracat faaliyetine girme maliyetini düşürdüğü, bu imkân sayesinde küçük firmaların ihracatçı olmalarının daha kolay hale geldiği gösterilmiştir. ${ }^{8}$

Meksika'daki üretim tesisleri verilerini kullanan araştırmada, bir bölgede ihracatçı firmaların kümelenmesinin olmasının ihracatçı olmayan bir firmanın ihracatçı olmasına katkısının olmadığını tespit edilmiştir. ${ }^{9}$ Birleșik Krallıktaki firmalar için coğrafi bilgi taşmalarının firmaların ihracatçı olmaları ihtimalini artırmadığı sonucuna ulaşılmıştır.10 İtalya'nın Düzey3 bölgeleri için yapılan araştırmada çevredeki bölgelerde ihracatçı firma bulunması sayesinde oluşan mekânsal ihracat bilgi yayılmalarının diğer bölgelerdeki firmaların

\footnotetext{
4 Paul Krugman, "Increasing Returns and Economic Geography", The Journal of Political Economy, Vol. 99, No. 3. 1991, ss. 483-499.

${ }^{5}$ Brain Aitken, Gordon Hanson ve E. Ann Harrison, "Spillovers, Foreign Investment, and Export Behavior", Journal of International Economics, 43, 1997, ss. 103-132 6 Pamina Koenig, "Agglomeration and the Export Decisions of French Firms", Journal of Urban Economics, 66: 2009, ss. 186-195

7 Peter Harasztosi, "Export and Import Spillovers in Hungary" http://www.eeaesem.com/files/papers/Eea-Esem/2011/2142/LocalSpillovers 2011.pdf

${ }^{8}$ Martin Andersson ve Hans Lööf, "Learning-by-Exporting Revisited: The Role of Intensity and Persistence", Scandinavian Journal of Economics, 111,2009, ss. 893-916.

${ }_{9}^{9}$ Brain Aitken, Gordon Hanson ve E.Ann Harrison, "Spillovers, Foreign Investment, and Export Behavior", Journal of International Economics, 43, 1997, ss. 103-132. ${ }^{10}$ Andrew Bernard ve Bradford Jensen, "Why Some Firms Export", The Review of Economics and Statistics, 86: 2004, ss. 561-569.
}

Sayfa/Page | 185

IGU J. Soc. Sci., 4 (1), 2017, pp. 181-196. 
Sayfa/Page | 186

İGÜ Sos. Bil. Derg., 4 (1), 2017, ss. $181-196$.

hem ihracatçı olmalarına katkı sağladığını, hem de ihracatçı olan firmaların ihracat miktarlarının artmasına olumlu katkı verdiğini tespit edilmiştir.11

\section{Mekânsal Ekonometrik Model}

Mekânsal analizin özünü "Bir bölgede meydana gelen şey (olay, faaliyet vs.) komşu bölgede meydana gelen şey (olay, faaliyet vs.) ile ilişkilidir." şeklinde tanımlamak mümkündür. Bu durumu daha özlü ve kısa olarak Coğrafyanın Birinci Kanunu olarak "Her şey başka her şey ile ilişkilidir, ancak birbirine yakın olan şeyler daha çok" şeklinde tanımlamıştır. ${ }^{12}$

Mekânsal etki olduğunda "EKK hata terimlerinin ilişkisiz olduğu varsayımı" geçersiz hale gelmektedir. Diğer taraftan bağımsız gözlemler varsayımı da ihlal edilmektedir. Sonuçta elde edilen tahminler etkin değildir ve yanlı bir kestiricidir. Bu sebeplerle ekonometrik analizlerde mekânsal etkinin de dikkate alınması gerekmektedir. ${ }^{13}$

\section{Mekânsal Ağırlık Matrisi}

Mekânsal etkileşim veya bağımlılık, mekânsal ağırlık matrisi (W) ile ifade edilir. $W_{y}$, komşu bölgelerdeki bağımlı değişken y'nin ortalama mekânsal ağırlığını göstermektedir. Komşuluk durumuna göre veya uzaklığa göre oluşturulan $(\mathrm{NxN})$ boyutundaki ağırlık matrisindeki elemanlar satır ve sütunlardaki ögelerin sınırdaş veya komşu olup olmadığını göstermektedir. Mekânsal bağımlılığı ekonometrik analize dâhil etmek için mekânsal gecikme operatörü kullanılır ve bu gecikme operatörü, komşu konumlardaki rassal değişkenlerin ağırlıklandırılmış bir ortalamasıdır. ${ }^{14}$

$$
\text { Mekânsal Ağırlık Matrisi }\left[\mathrm{W}_{\mathrm{y}}\right]=\sum_{\mathrm{j}=1}^{\mathrm{N}} \mathrm{w}_{\mathrm{ij}} \mathrm{y}_{\mathrm{j}} \text { şeklindedir. }
$$

Bu çalışma için vezir komşuluk kuralı esas alınarak Düzey2 Bölgeleri için 26x26boyunda ağırlık matrisi oluşturulmuştur. Panel veri modellerinde yatay kesit veri için oluşturulan ağırlık matrisinin karesi alınarak panel veri ağırlık matrisi oluşturulması gerekmektedir Bu çalışmada Panel Veri Yöntemi için kullanılan ağırlık matrisleri ise hazırlanan esas itibarıyla yatay kesit veri için hazırlanmış olan 26x26 boyutundaki ağırlık matrislerinin Stata Programı ile genişletilerek olușturulmuştur.

11 Mariasole Bannò, Diego Giuliani ve Enrico Zaninotto, "The Nature of Export Spillovers on Trade: An Analysis at the Nuts 3 Level in Italy", Applied Economic Letters, 2015, Vol 22, No 15, ss. 815-819.

${ }^{12}$ Fatma Zeren, “Mekânsal Etkileşim Analizi”, Ekonometri ve İstatistik Sayı, 12 2010, ss. 18-39.

13 a.g.e

14 a.g.e 


\section{Mekânsal Bağımlılığın Modellenmesi}

Mekânsal Bağımlılık Mekânsal Gecikmeli Süreç ve Mekânsal Hata Süreci olmak üzere iki ana süreç üzerinden modellenebilir. Yatay kesit veri Mekânsal Gecikmeli Süreç,

$$
y_{i}=\rho W y_{i}+\beta x_{i}+u_{i} u_{i} \sim N\left(0, \sigma_{u}^{2}\right)
$$

şeklinde tanımlanabilir.

Mekânsal ekonometrik modeller oluşturulurken gecikmeli bağımlı değişken, açılklayıcı değişken olarak modele dâhil edilir. Y, (nx1)boyutlu konumlar boyunca gözlenen bağımlı değişken vektörüdür ve $\mathrm{x}$, (n x k)boyutlu açıklayıcı değişkenler vektörüdür. W,(nxn)boyutlu mekânsal ağırlık matrisidir. $\rho$ komşu konumlardaki y'lerin ilgili konumdaki y üzerindeki etkisini ölçen otoregresif parametredir ve çoğu durumda $-1<\rho<1$ kabul edilir. 15

Mekânsal Hata Süreci ise,

$$
\begin{aligned}
& \mathrm{y}_{\mathrm{i}}=\beta \mathrm{x}_{\mathrm{i}}+\mathrm{u}_{\mathrm{i}} \quad \text { (4) } \\
& \mathrm{u}_{\mathrm{i}}=\lambda W \mathrm{Wu}_{\mathrm{i}}+\varepsilon \epsilon_{\mathrm{i}} \sim \mathrm{N}\left(0, \sigma_{\varepsilon}^{2}\right) \quad \text { olarak tanımlanabilir. }
\end{aligned}
$$

$\lambda$ ilgili konumun hata terimi ile komşu konumların hata terimleri arasındaki mekânsal bağımlılığın derecesini ölçer ve genellikle 1'den küçüktür.

\section{Model}

Bölgelerin ihracat ürün deseni çeşitliliği çok sayıda dışsal faktöre, ihracatçı firmaların yapısı, yönetim ve pazarlama politikaları gibi çok sayıda da içsel faktöre bağlıdır. Bu çalışmada bu faktörlerin bölgeler için aynı olduğu kabul edilerek bölgelere özgü değerler alan değişkenler kullanılarak bir model oluşturulmuştur.

Türkiye'nin ihracatının yoğun olarak ithal ara girdi mallarına bağlı olması nedeniyle bölgelerin ihracat ürünü çeşitliliği ithalat miktarından etkilenmektedir. Bölgelerdeki ihracatçı firma sayısının artması da ürün çeşitliliğini etkilemektedir. Bu sebeplerle aşağıdaki model oluşturulmuştur.

Bölgelerin ihraç ürünü çeşitliliği Armonize Sistem HS6 bazında çeyrek dönemde ihraç ettikleri ürün sayısı olarak alınmıştır. Bölgelerin HS6 bazında

${ }^{15}$ A.g.e. 
Sayfa/Page | 188

İGÜ Sos. Bil. Derg., 4 (1), 2017, ss. $181-196$.

10 Bin Doların üzerinde yaptıkları ihracatlar değerlendirmeye alınmıștır. Resmi adı Armonize Mal Tanımı ve Kodlama Sistemi (The Harmonized Commodity Description and Coding Systems) olan Armonize Sistem, uluslararası ticarete konu olan tüm mallar için kullanılan uluslararası bir ticari sinıflandirma sistemidir.

Armonize Sistem (Tarife Cetveli) 21 bölüm ve 96 fasıldan oluşmaktadır. Fasillar 2'li kodlara, her bir fasıl 4'lü kod olan pozisyonlara ve her bir pozisyon ise 6'lı kod olan alt pozisyonlara ayrılmıştır. Her ülkenin tarife cetvelindeki 2'li, 4'lü ve 6'lı kodları tüm dünyada aynıdır. Armonize Sistem'de 6'lı koddan sonraki bölümleri, ülkeler kendi ihtiyaçlarına (detaylı istatistik almak ve gümrük vergilerini daha detay ürün bazında uygulamak için) göre detaylandırabilmektedir. Türkiye'de ürünler en detay bazda 12'li kodla sınıflandırılmaktadır. Türkiye, Avrupa Birliği ile Ortak Gümrük Birliğine sahip olmasından dolayı, Türkiye'nin 8'li bazdaki kodları ve ürün grupları Avrupa Birliği ülkeleri ile aynıdır. ${ }^{16}$

$$
\mathbf{P D}_{\text {it }}=\mathrm{IM}_{\mathrm{it}}+\mathrm{FS}_{\mathrm{it}}+\mathbf{E X}_{\mathrm{it}}
$$

$\mathrm{EX}_{\text {it }}$ : i Bölgesinin t Dönemindeki İhracatı Logaritması

$\mathrm{IM}_{\mathrm{it}}$ : i Bölgesinin t Dönemindeki İthalatı Logaritması

$\mathrm{FS}_{\text {it }}$ : i Bölgesindeki t Dönemindeki İhracatçı Firma Sayısı Logaritması

PD : i Bölgedeki t Dönemindeki HS6 Bazında İhracat edilen Ürün Sayısı Logaritması

Çalışmada aynı zamanda bölgelerin birbirlerinin ihracat pazarı çeşitliliğine etkisi de incelenmiştir. Pazar sayısı tespit edilirken bölgelerin çeyrek dönem içinde 10 Bin Dolar üzerinde ihracat yaptıkları ülke veya serbest ticaret bölgeleri dikkate alınmıştır. Modelde bağımlı değişken olarak Pazar Sayısı (PS) kullanılmıştır.

\section{Veri}

Türkiye'de bulunan 26 Düzey2 Bölgesinin 2002-2015 (son iki çeyrek hariç) dönemine ait çeyrek dilimlerdeki ihracat, ithalat, ihracatçı firma sayısı, ihraç ürün sayısı ve pazar sayısı verileri kullanılmıştır. 2015 yılı için ilk iki çeyrek olmak üzere toplam 54 çeyrek dönem veri bulunmaktadır. Veriler TÜİK, Gümrük ve Ticaret Bakanlığı (GTB) ve Ekonomi Bakanlığından temin edilmiştir. Verilerin logaritması alınarak değişkenlerin hassasiyetleri hakkında yorum yapılabilmesi de amaçlanmıştır. Düzey2 bölgelerine ilişkin 2014 yılı bazı diş ticaret verileri Tablo-2'de verilmiştir.

${ }^{16}$ http://www.gtb.gov.tr/2014-yili-gumruk-tarife-cetveli. 
Tablo 2: Düzey 2 Bölgelerinin Bazı Dış Ticaret Verileri (2014)

\begin{tabular}{|c|c|c|c|c|c|c|}
\hline Bölge & İller & $\begin{array}{l}\text { İhracat } \\
\text { (Milyon \$) }\end{array}$ & $\begin{array}{l}\text { İthalat } \\
\text { (Milyon \$) }\end{array}$ & $\begin{array}{l}\text { İhracatçı } \\
\text { Firma } \\
\text { Sayısı }\end{array}$ & $\begin{array}{l}\text { İhracat } \\
\text { Fasıl } \\
\text { Sayısı } \\
\text { (HS2) }\end{array}$ & $\begin{array}{l}\text { İthalat } \\
\text { Fasıl } \\
\text { Sayısı } \\
\text { (HS2) }\end{array}$ \\
\hline TR10 & İstanbul & 82.047 & 136.021 & 26581 & 97 & 97 \\
\hline TR21 & $\begin{array}{l}\text { Tekirdağ, Edirne, } \\
\text { Kurklareli }\end{array}$ & 1.439 & 1.336 & 2007 & 83 & 89 \\
\hline TR22 & Balıkesir, Çanakkale & 687 & 590 & 1528 & 73 & 80 \\
\hline TR31 & İzmir & 9,615 & 9.931 & 4509 & 96 & 97 \\
\hline TR32 & Aydın, Denizli, Muğla & 3.902 & 2.549 & 3407 & 90 & 90 \\
\hline TR33 & $\begin{array}{l}\text { Manisa, Afyon, } \\
\text { Kütahya, Ușak }\end{array}$ & 2.793 & 3.910 & 3832 & 81 & 87 \\
\hline TR41 & $\begin{array}{l}\text { Bursa, Eskişehir, } \\
\text { Bilecik }\end{array}$ & 10.300 & 9.079 & 7582 & 95 & 96 \\
\hline TR42 & $\begin{array}{l}\text { Kocaeli, Sakarya, } \\
\text { Düzce, Bolu, Yalova }\end{array}$ & 12.039 & 11.591 & 3982 & 95 & 96 \\
\hline TR51 & Ankara & 8.102 & 1.098 & 5712 & 96 & 96 \\
\hline TR52 & Konya, Karaman & 1.849 & 1.460 & 3550 & 93 & 86 \\
\hline TR61 & $\begin{array}{l}\text { Antalya, Isparta, } \\
\text { Burdur }\end{array}$ & 1.364 & 880 & 1912 & 91 & 91 \\
\hline TR62 & Adana, Mersin & 3.625 & 3.862 & 2957 & 95 & 94 \\
\hline TR63 & $\begin{array}{l}\text { Hatay, } \\
\text { Kahramanmaraş, } \\
\text { Osmaniye }\end{array}$ & 3.115 & 5.493 & 1909 & 93 & 82 \\
\hline TR71 & $\begin{array}{l}\text { Kırıkkale, Aksaray, } \\
\text { Niğde, Nevşehir }\end{array}$ & 428 & 350 & 1143 & 73 & 72 \\
\hline TR72 & Kayseri, Sivas, Yozgat & 1.993 & 1.783 & 2292 & 86 & 82 \\
\hline TR81 & $\begin{array}{l}\text { Zonguldak, Karabük, } \\
\text { Bartın }\end{array}$ & 733 & 1.819 & 361 & 59 & 61 \\
\hline TR82 & $\begin{array}{l}\text { Kastamonu, Çankırı, } \\
\text { Sinop }\end{array}$ & 138 & 166 & 550 & 60 & 61 \\
\hline TR83 & $\begin{array}{l}\text { Samsun, Tokat, Çorum, } \\
\text { Amasya }\end{array}$ & 844 & 1.148 & 1840 & 82 & 86 \\
\hline TR90 & $\begin{array}{l}\text { Trabzon, Ordu, } \\
\text { Giresun, Rize, Artvin }\end{array}$ & 2.129 & 247 & 1390 & 91 & 75 \\
\hline TRA1 & $\begin{array}{l}\text { Erzurum, Erzincan, } \\
\text { Bayburt }\end{array}$ & 40 & 59 & 356 & 65 & 48 \\
\hline TRA2 & $\begin{array}{l}\text { Ağrı, Kars, Iğdır, } \\
\text { Ardahan }\end{array}$ & 207 & 85 & 199 & 87 & 66 \\
\hline TRB1 & $\begin{array}{l}\text { Malatya, Elazı̆̆, Bingöl, } \\
\text { Tunceli }\end{array}$ & 553 & 111 & 991 & 73 & 69 \\
\hline TRB2 & $\begin{array}{l}\text { Van, Muș, Bitlis, } \\
\text { Hakkâri }\end{array}$ & 427 & 118 & 324 & 75 & 50 \\
\hline TRC1 & $\begin{array}{l}\text { Gaziantep, Adıyaman, } \\
\text { Kilis }\end{array}$ & 7.036 & 5.890 & 3082 & 92 & 87 \\
\hline TRC2 & Şanlıurfa, Diyarbakır & 505 & 305 & 866 & 72 & 69 \\
\hline TRC3 & $\begin{array}{l}\text { Mardin, Batman, } \\
\text { Şırnak, Siirt }\end{array}$ & 1.686 & 256 & 407 & 88 & 65 \\
\hline
\end{tabular}

Kaynak: TÜIKK 
Sayfa/Page | 190

İGÜ Sos. Bil. Derg.,

4 (1), 2017 ss. 181-196

Modelde bulanan ihracat (İHR), İthalat (İTH), İhracatçı Firma Sayısı (FS), Ürün Sayısı (PD) ve Pazar Sayısı (PS)değişkeleri için önce birim kök testleri uygulanmış ve değişkenlerin düzeyde durağan olmadığı, birinci farkları alındığında durağan hale geldikleri görülmüştür. Serilere Panel Eşbütünleşme Testi de uygulanmıştır. Birim kök testi ve eşbütünleşme testi sonuçları aşağıdaki tablolarda verilmiştir. Sonuçlara göre, değişkenler arasında eşbütünleşmenin bulunduğu görülmektedir. Bu sonuç modele dâhil edilen değişkenlerin uygun olduğunun bir göstergesi olarak kabul edilebilir.

Tablo 3: İhracat Ürün Sayısı Panel Birim Kök Testi Sonuçları

\begin{tabular}{|l|l|l|}
\hline Test & Düzev P-Değeri & Birinci Fark P-Değeri \\
\hline Levin, Lin \& Chu & 0.1656 & 0.0000 \\
\hline Im, PesaranandShin W- & 0.1765 & 0.0000 \\
\hline ADF - FisherChi-square & 0.1866 & 0.0000 \\
\hline PP - FisherChi-square & 0.1734 & 0.0000 \\
\hline
\end{tabular}

Tablo 4: İthalat Panel Birim Kök Testi Sonuçları

\begin{tabular}{|l|l|l|}
\hline Test & Düzey P-Değeri & Birinci Fark P-Değeri \\
\hline Levin, Lin \& Chu & 0.1652 & 0.0000 \\
\hline Im, PesaranandShin W- & 0.1564 & 0.0000 \\
\hline ADF - FisherChi-square & 0.1890 & 0.0000 \\
\hline PP - FisherChi-square & 0.1920 & 0.0000 \\
\hline
\end{tabular}

Tablo 5: Firma Sayısı Panel Birim Kök Testi Sonuçları

\begin{tabular}{|l|l|l|}
\hline Test & Düzev P-Değeri & Birinci Fark P-Değeri \\
\hline Levin, Lin \& Chu & 0.9990 & 0.0000 \\
\hline Im, PesaranandShin W- & 0.2218 & 0.0000 \\
\hline ADF - FisherChi-square & 0.1280 & 0.0000 \\
\hline PP - FisherChi-square & 0.1360 & 0.0000 \\
\hline
\end{tabular}

Tablo 6: İhracat Birim Kök Testi Sonuçları

\begin{tabular}{|l|l|l|}
\hline Test & Düzev P-Değeri & Birinci Fark P-Değeri \\
\hline Levin, Lin \& Chu & 0.0799 & 0.0000 \\
\hline Im, PesaranandShin W- & 0.9210 & 0.0000 \\
\hline ADF - FisherChi-square & 0.9549 & 0.0000 \\
\hline PP - FisherChi-square & 0.9010 & 0.0000 \\
\hline
\end{tabular}


Tablo 7: Pedroni Eşbütünleşme Testi (Ürün, İthalat, Firma Sayısı, İhracat)

\begin{tabular}{|l|l|l|l|l|}
\hline & Statistic & P & W. Statistic & P \\
\hline Panel v-Statistic & 0.007555 & 0.4877 & -1.702488 & 0.9230 \\
\hline $\begin{array}{l}\text { Panel rho- } \\
\text { Statistic }\end{array}$ & 1.42022 & 0.9188 & 1.636667 & 0.9477 \\
\hline Panel PP-Statistic & -1.793458 & 0.0288 & -3.461985 & 0.0001 \\
\hline $\begin{array}{l}\text { Panel ADF- } \\
\text { Statistic }\end{array}$ & -2.322211 & 0.0110 & -4.653520 & 0.0000 \\
\hline $\begin{array}{l}\text { Grouprho- } \\
\text { Statistic }\end{array}$ & 3.997675 & 0.0070 & - & - \\
\hline $\begin{array}{l}\text { Group PP- } \\
\text { Statistic }\end{array}$ & -3.422290 & 0.0001 & - & - \\
\hline $\begin{array}{l}\text { Group ADF- } \\
\text { Statistic }\end{array}$ & -4.328880 & 0.0000 & - & - \\
\hline
\end{tabular}

Sayfa/Page | 191

\section{Bulgular \\ İhracat Ürün Çeşitliliği}

Düzey 2 bölgelerinin birbirlerinin ihracat ürün çeşitliliği üzerine etkisini araştırmak için önce (5) numaralı model kullanılmıştır. Önce En Küçük Kareler (EKK) tahmini yapılmıştır. Daha sonra Mekânsal Hata Modeli (SEM) ve Mekânsal Gecikme Modeli (SAR) tahmin edilmiştir. Sonuçlar Langrange Çarpanı (LM) Testi Mekânsal Hata Modelinin geçerli olduğunu; yani bölgelerarası korelasyonel ilişkiyi ifade eden mekânsal bağımlılığın ana modelde değil; hata terimlerinde olduğunu göstermektedir. LM test sonuçları Tablo-8'de verilmiştir.

Tablo 8: Mekânsal Bağımlılık Testi Sonuçları

\begin{tabular}{|l|l|l|}
\hline & Değer & P-Değeri \\
\hline LM $_{\text {LAG }}$ & 0.2422 & 0.4118 \\
\hline LMR $_{\text {LAG }}$ & 0.2004 & 0.5899 \\
\hline LM $_{\text {ERR }}$ & 52.6627 & 0.0000 \\
\hline LMR $_{\text {ERR }}$ & 51.1888 & 0.0000 \\
\hline
\end{tabular}

Mekân etkisinin tespit edilmesinden sonra ise, Sabit Etkiler ve Rastsal Etkiler Panel Modellerinden hangisinin geçerli olduğunu tespit etmek için Hausman Testi uygulanmıştır. Tablo-9'da verilen sonuçlar uygun modelin Sabit Etkiler Mekânsal Panel Veri Modeli olduğunu göstermektedir.

Rastsal Etkiler Mekânsal Gecikmeli Panel Modeli'nin fonksiyonel formu şöyledir:

$$
P D_{i t}=\beta_{0}+p W P D_{i t}+\beta_{1} I T H_{i t}+\beta_{1} F S_{i t}+\beta_{3} E X_{i t}+u_{i t}
$$


Sayfa/Page | 192

İGÜ Sos. Bil. Derg., 4 (1), 2017, ss. $181-196$
Rastsal Etkiler Mekânsal Hata Panel Modeli'nin fonksiyonel formu ise şöyledir:

$$
\begin{aligned}
& P D_{i t}=\beta_{0}+\beta_{1} I T H_{i t}+\beta_{1} F S_{i t}+\beta_{3} E X_{i t}+u_{i t} \\
& u_{i t}=\lambda W u_{i t}+\varepsilon_{i t}, E\left(\varepsilon_{i t}\right)=0, \operatorname{Var}\left(\varepsilon_{i t}\right)=\sigma^{2}
\end{aligned}
$$

\begin{tabular}{|c|c|c|c|c|c|}
\hline & P-OLS & SAR-FE & SAR-RE & SEM-FE & SEM-RE \\
\hline $\mathrm{C}$ & $\begin{array}{l}1.453228 \\
(0.000)\end{array}$ & ------- & $\begin{array}{l}1.02267 \\
(0.120)\end{array}$ & ------- & $\begin{array}{l}1.5551 \\
(0.001)\end{array}$ \\
\hline $\mathrm{ITH}_{\mathrm{it}}$ & $\begin{array}{l}0.176320 \\
(0.000)\end{array}$ & $\begin{array}{l}0.13336 \\
(0.054)\end{array}$ & $\begin{array}{l}0.137400 \\
(0.059)\end{array}$ & $\begin{array}{l}0.179002 \\
(0.000)\end{array}$ & $\begin{array}{l}0.157599 \\
(0.000)\end{array}$ \\
\hline $\mathrm{FS}_{\text {it }}$ & $\begin{array}{l}0.211156 \\
(0.000)\end{array}$ & $\begin{array}{l}0.143239 \\
(0.120)\end{array}$ & $\begin{array}{l}0.13880 \\
(0.179)\end{array}$ & $\begin{array}{l}1.2111 \\
(0.000)\end{array}$ & $\begin{array}{l}0.199340 \\
(0.000)\end{array}$ \\
\hline $\mathrm{EX}_{\mathrm{it}}$ & $\begin{array}{l}0.212346 \\
(0.000)\end{array}$ & $\begin{array}{l}0.16663 \\
(0.019)\end{array}$ & $\begin{array}{l}0.160500 \\
(0.032)\end{array}$ & $\begin{array}{l}0.16220 \\
(0.0478)\end{array}$ & $\begin{array}{l}0.166001 \\
(0.010)\end{array}$ \\
\hline Spat.Aut. $(\lambda)$ & ----- & ------ & ------- & $\begin{array}{l}0.085990 \\
(0.001)\end{array}$ & $\begin{array}{l}0.084977 \\
(0.000)\end{array}$ \\
\hline Spat.Aut. $(\rho)$ & ----- & $\begin{array}{l}0.099100 \\
(0.000)\end{array}$ & $\begin{array}{l}0.09453 \\
(0.000)\end{array}$ & ------ & ------- \\
\hline $\mathrm{R}^{2}$ & 0.88022 & 0.8600 & 0.8522 & 0.8900 & 0.8998 \\
\hline \multicolumn{3}{|l|}{ Hausman Test } & \multicolumn{3}{|c|}{$34.50(0.0000)$} \\
\hline
\end{tabular}

Tablo 9: Tahmin Sonuçları

Sabit Etkili Mekânsal Panel modeli tahmin sonuçlarına göre, mekânsal otokorelasyon katsayısı $(\lambda) 0.08^{\prime}$ dur. Katsayının işareti pozitif olduğundan bölgelerin birbirlerinin ürün çeşitliliği sayısı arasında çok az da olsa pozitif yönlü bir etki bulunmaktadır. Ancak etkinin çok küçük olduğu görülmektedir. Komşu bölgelerde ihraç ürünü sayısının artması söz konusu bir bölgedeki ihraç ürün sayısının artmasına katkı sağlamaktadır. Düzey2 bölgeleri için ithalatın \%1 artması ürün çeşitliliğini $\% 0.15$ artırmaktadır. İhracatçı firma sayısının $\% 1$ artması çeşitliliği \%0.19 artırırken, ihracatın \%1 artması ise ürün çeşitliliğinin \%0.16 artmasını sağlamaktadır.

\section{İhracat Pazar Çeşitliliği}

$\mathrm{Bu}$ bölümde bölgelerin birbirlerinin ihracat pazar sayısına etkisi incelenmiştir. Önceki bölümde olduğu gibi veri serileri için birim kök testi ve eşbütünleşme testi uygulanmıştır. Test sonuçları serilerin düzeyde durağan olmadığını ancak birinci fark alındığında durağan hale geldiğini göstermektedir. Değişkenler arasında uzun dönemli bir ilişki yani eşbütünleşme bulunmaktadır. Test sonuçları aşağıdaki tablolarda verilmiştir. 
Tablo 10: Pazar Sayısı Panel Birim Kök Testi Sonuçları

\begin{tabular}{|l|l|l|}
\hline Test & Düzev P-Değeri & Birinci Fark P-Değeri \\
\hline Levin, Lin \& Chu & 0.999 & 0.0000 \\
\hline Im, PesaranandShin W- & 0.999 & 0.0000 \\
\hline ADF - FisherChi-square & 0.999 & 0.0000 \\
\hline PP - FisherChi-square & 0.999 & 0.0000 \\
\hline
\end{tabular}

Tablo 11: İthalat Panel Birim Kök Testi Sonuçları

\begin{tabular}{|l|l|l|}
\hline Test & Düzev P-Değeri & Birinci Fark P-Değeri \\
\hline Levin, Lin \&Chu & 0.999 & 0.0000 \\
\hline Im, PesaranandShin W- & 0.999 & 0.0000 \\
\hline ADF - FisherChi-square & 0.999 & 0.0000 \\
\hline PP - FisherChi-square & 0.999 & 0.0000 \\
\hline
\end{tabular}

Sayfa/Page | 193

Tablo 12: Firma Sayısı Panel Birim Kök Testi Sonuçları

\begin{tabular}{|l|l|l|}
\hline Test & Düzev P-Değeri & Birinci Fark P-Değeri \\
\hline Levin, Lin \&Chu & 1.0000 & 0.0000 \\
\hline Im, PesaranandShin W- & 1.0000 & 0.0000 \\
\hline ADF - FisherChi-square & 0.9700 & 0.0000 \\
\hline PP - FisherChi-square & 0.9100 & 0.0000 \\
\hline
\end{tabular}

Tablo 13: İhracat Panel Birim Kök Testi Sonuçları

\begin{tabular}{|l|l|l|}
\hline Test & Düzev P-Değeri & Birinci Fark P-Değeri \\
\hline Levin, Lin \&Chu & 0.4568 & 0.0000 \\
\hline Im, PesaranandShin W- & 0.5899 & 0.0000 \\
\hline ADF - FisherChi-square & 0.9022 & 0.0000 \\
\hline PP - FisherChi-square & 0.9512 & 0.0000 \\
\hline
\end{tabular}

Tablo 14: Pedroni Eşbütünleşme Testi (Pazar, İthalat, Firma Sayısı, İhracat)

\begin{tabular}{|l|l|l|l|l|}
\hline & Statistic & P & W. Statistic & P \\
\hline Panel v-Statistic & -0.680799 & 0.7520 & -2.184843 & 0.9855 \\
\hline Panel rho-Statistic & 1.554994 & 0.9400 & 3.816753 & 0.9999 \\
\hline Panel PP-Statistic & -9.038174 & 0.0000 & -5.476083 & 0.0000 \\
\hline $\begin{array}{l}\text { Panel ADF- } \\
\text { Statistic }\end{array}$ & -10.20723 & 0.0000 & -7.663721 & 0.0000 \\
\hline Grouprho-Statistic & 7.276543 & 0.9989 & - & - \\
\hline Group PP-Statistic & -8.771021 & 0.0000 & - & - \\
\hline $\begin{array}{l}\text { Group ADF- } \\
\text { Statistic }\end{array}$ & -8.628986 & 0.0000 & - & - \\
\hline
\end{tabular}

Bölgeler arasında mekânsal etkinin olup olmadığı tespit etmek ve uygun modeli seçmek için Langrange Çarpanı (LM) Testi uygulanmıştır. Sonuçlar Düzey2 bölgeleri arasında pazar sayısı konusunda mekânsal etkinin olmadığını göstermektedir. Bölgelerin birbirlerinin ihraç pazarı sayısına etki etmemektedir. LM test sonuçları Tablo-15'te verilmiştir. 
Tablo 15: Mekânsal Bağımlılık Testi Sonuçları

\begin{tabular}{|l|l|l|l|}
\hline & Değer & P-Değeri \\
\cline { 2 - 4 } & LM $_{\text {LAG }}$ & 8.7640 & 0.2344 \\
\hline LMR $_{\text {LAG }}$ & 8.1711 & 0.1500 \\
\cline { 2 - 4 } Sayfa/Page | 194 & 38.3299 & 0.2110 \\
\hline LM $_{\text {ERR }}$ & 37.7661 & 0.1812 \\
\hline
\end{tabular}

Model En Küçük Kareler yöntemi ile tahmin edilmiştir. Sonuçlar Tablo-

16 'da verilmiştir.

Tablo 16: Tahmin Sonuçları

\begin{tabular}{|l|l|l|l|}
\hline $\mathrm{C}$ & $\mathrm{ITH}_{\text {it }}$ & $\mathrm{FS}_{\text {it }}$ & $\mathrm{EX}_{\text {it }}$ \\
\hline $0.005545(0.000)$ & $0.0867868(0.000)$ & $0.0469912(0.001)$ & $0.09956(0.005)$ \\
\hline
\end{tabular}

$\mathrm{Bu}$ durumda uygun model Havuzlanmış-EKK modelidir. $\mathrm{Bu}$ model sonuçlarına göre, ithalatın, ihracatçı firma sayısının ve ihracatın \%1 artması ihracat pazar sayısını sırasıyla \%0.08, \%0.04 ve \%0.09 artırmaktadır. Etkiler ihmal edilebilecek kadar düşük düzeydedir.

\section{Sonuç}

Bu çalışmada Düzey2 bölgelerin birbirlerinin ihracat ürün çeşitliliğini etkileyip etkilemedikleri, bölgeler arasında mekânsal etkinin olup olmadığı araştırılmıştır. Bu kapsamda Türkiye'deki 26 Düzey2 bölgesi arasındaki etki Mekânsal Panel Veri Yöntemi kullanılarak incelenmiştir. Mekânsal ağırlık matrisi vezir komşuluğu kuralına göre oluşturulmuştur.

Düzey2 bölgeleri için yapılan LM testi sonuçları uygun Mekânsal Ekonometrik Modelin Mekânsal Hata Modeli (SEM) olduğunu göstermektedir. Bölgelerarası korelasyonel ilişkisi yani mekânsal bağımlılığın ana modelde değil; hata terimlerindedir. Hausman Testi sonuçlarına göre ise uygun panel veri modeli ise Sabit Etkili Panel Veri Modelidir. Sabit Etkili Mekânsal Panel Veri Modeli tahmininden elde edilen sonuçlara göre; mekânsal otokorelasyon katsayısı $(\lambda) 0.084$ 'tür. Katsayının işareti pozitif olduğundan bölgelerin ihracat ürün sayıları arasında pozitif yönlü bir etki bulunmaktadır.. Katsayının çok küçük olması etkinin de çok küçük olduğu göstermektedir. Komşu bölgelerde ihraç ürünü sayısının artması söz konusu bir bölgedeki ihraç ürün sayısının artmasına katkı sağlamaktadır. Düzey2 bölgeleri için ithalatın \%1 artması ürün çeșitliliğini \%0.15 artırmaktadır. İhracatçı firma sayısının \%1 artması çeşitliliği \%0.19 artırırken, ihracatın $\% 1$ artması ise çeşitliliğin \%0.16 artmasını sağlamaktadır

LM testi sonuçlarına göre, Düzey2 bölgelerinin birbirlerinin ihracat pazar sayılarına etkisi bulunmamaktadır. Mekânsal etki bulunmadığından HEKK tahmini yapılmıştır.Düzey2 bölgeleri geneli için ithalatın, ihracatçı firma 
sayısının ve ihracatın $\% 1$ artması ihracat pazar sayısını sırasıyla $\% 0.08$, $\% 0.04$ ve \%0.09 artırmaktadır. Etkiler ihmal edilebilecek kadar düşük düzeydedir.

Bölgelerin birbirlerinin ihracat ürünü çeşitliliğine çok az da olsa etkisinin bulunması ülkenin genel ihracatının ve ihraç ürünü sayısının artırılmasına olumlu katkı yapabilecek bir husustur. Bölgelerin birbirlerinden öğrenmesini kolaylaştıracak politikalar geliştirilmesi, bu yönde destek ve teşvikler sağlanması hem firmalara hem de ülkeye çok yararlı olacaktır. Genel olarak ülke için yatay çeşitlendirme olan bu etkinin inovasyon yoluyla dikey çeşitlendirmeye de dönüştürülmesi de ülkenin ihracat performansını artıracaktır. Bu sebeple dikey çeşitliliğe yönelik ARGE ve ürün geliştirme desteklerinin artırılması için politikalara önem verilmesi gerekmektedir.

\section{KAYNAKÇA}

ANSELIN, L., "Spatial Econometrics: Methods and Models", Kluwer Academic Publishers, NY, 1998.

AITKEN, Brain, Gordon HANSON ve E. Ann HARRISON, "Spillovers, Foreign Investment, and Export Behavior", Journal of International Economics, 43, 1997, ss. 103-132.

ANDERSSON, Martin ve Hans LÖÖF, "Learning-by-Exporting Revisited: The Role of Intensity and Persistence", Scandinavian Journal of Economics, 111, 2009, ss. 893-916.

ANDERSSON, Martin ve J. Frederic WEISS, “External Trade and Internal Geography - A Test of Local Export Spillovers", Micro-Dyn Working Paper, no. 35/10.2012.

BECHHETTI, Leonardo ve Stefania ROSSI, "The Positive Effect of Industrial District on the Export Performance of Italian Firms", Review of Industrial Organization, 16, 2000, ss.53-68.

BERNARD, Andrew ve Bradford JENSEN, "Why Some Firms Export", The Review of Economics and Statistics, 86: 2004, ss. 561-569.

BANNÒ, Mariasole, Diego GIULIANI ve Enrico ZANINOTTO, "The Nature of Export Spillovers on Trade: An Analysis at the Nuts 3 Level in Italy", Applied Economic Letters, 2015, Vol 22, No 15, ss. 815-819.

BONAGLIA, Federico ve Kiichiro FUKASAKU, "Export Diversification in Low-Income Countries: An International Challenge After Doha," OECD Working Paper No. 209. 2003.

CADOT, Oliver, Celine CARRERE ve Vanessa STRAUSS-KAHN, "Export Diversification: What's behind the Hump?", Review of Economics and Statistics, Vol.93, No:2, 2001, ss. 590-605. 
Sayfa/Page | 196

İGÜ Sos. Bil. Derg.,

4 (1), 2017,

ss. $181-196$
GUTIERREZ de PINERES, Sheila ve Michael FERRANTINO, "Export Diversification and Structural Change: Some Comparisons for Latin America," 1997, SSRN Working Paper No. 36321.

HARASZTOSI, Peter, "Export and Import Spillovers in Hungary" http://www.eea-esem.com/files/papers/ Eea-Esem/2011/2142/Local Spillovers 2011.pdf

IMBS, Jean ve Romain WACZIARG, "Stages of Diversification", American Economic Review, 93 (1): 2003, ss. 63-86.

KOENIG, Pamina, "Agglomeration and the Export Decisions of French Firms", Journal of Urban Economics, 66: 2009, ss. 186-195.

KOENIG, Pamina, Florian MAYNERIS ve Sandra PONCET, "Local Export

Spillovers in France”, European Economic Review, 54 (4), 2010, ss. 622-641. KRUGMAN, Paul, "Increasing Returns and Economic Geography", The

Journal of Political Economy, Vol. 99, No. 3. 1991, ss. 483-499.

ZEREN, Fatma, “Mekânsal Etkileşim Analizi”, Ekonometri ve İstatistik

Sayı: 12, 2010, ss. 18-39.

\section{Summary}

The purpose of this study is to examine whether NUTS 2 Regions in Turkey affect eachothers' export product diversity by using Spatial Panel Data Method. Study uses quarterly export, import data of the regions. Spatial Weigh tMatrix was constructed by using queen contiguity rule. LM test was employed to determine existence of spatia leffect among regions and to choose the right spatial model between SpatialLag Model (SAR) and Spatial Error Model (SEM). LM test results show that there exists spatial effect among NUTS2 the regions and the best model is SEM. Hausman test results indicate the best model for the study is fixed effect panel model.

The results indicate NUTS2 regions have very weak spatial effect on eachothers export product diversitywhich means regions learn from eachother. This effect can be called as export spilover effect or positive externality in foreign trade. Exporter firms in the neighboring regions can diversify their export product basket by learning from each other which increases export of the country. Study did not find any spatial effect for export market diversification. NUTS2 regions do not have any effect on each others' export market diversity. That result also shows that while product information can diffuse among the regions, it is not possible to see market information spillover among them. 